\title{
Study of spray collapse phenomenon at flash boiling conditions using simultaneous front and side view imaging
}

\author{
Jianguo Du ${ }^{\mathrm{a}}$, Balaji Mohan ${ }^{\mathrm{a}, *}$, Jaeheon Sim ${ }^{\mathrm{b}}$, Tiegang Fang ${ }^{\mathrm{c}}$, William L \\ Roberts $^{\mathrm{a}}$ \\ ${ }^{a}$ Clean Combustion Research Center, King Abdullah University of Science and \\ Technology, Thuwal, Makkah Province, Saudi Arabia \\ ${ }^{b}$ Fuel Technology Division, R\&DC, Saudi Aramco, Dhahran, Eastern Province, Saudi \\ Arabia \\ ${ }^{c}$ Department of Mechanical and Aerospace Engineering, North Carolina State University, \\ Raleigh, NC 27695, United States
}

\begin{abstract}
Flash boiling has become a topic of interest to researchers due to its potential of achieving good fuel atomization and negative influence on GDI engine emissions when spray collapses and spray-wall impingement exists. Under flash boiling conditions, the accompanying spray collapse phenomenon and plume interaction are not clearly elucidated. Simultaneous side view diffused back illumination (DBI) and front view Mie-scattering were implemented in this work to capture transient plume to plume interaction of iso-octane fuel spray from a 10 hole gasoline direct injection (GDI) injector at flash boiling conditions. Fuel temperature and ambient gas pressure were varied in a wide range to cover collapse, transitional and non-flashing regimes. Two new criteria named 'spray collapse percentage', defined based on the front view Mie-scattering technique and 'optical thickness' based on the side view DBI
\end{abstract}

\footnotetext{
${ }^{*}$ Corresponding author: balaji.mohan@kaust.edu.sa
} 
technique, were developed for classification of different spray regimes. These two criteria distinguish the collapsing and transitional regimes well from the non-collapsing regime compared to other criteria used in the literature.

Keywords: Flash boiling; Spray collapse; Plume interaction; Gasoline direct injection (GDI) engine; Front, side view comparison

\section{Graphical abstract}
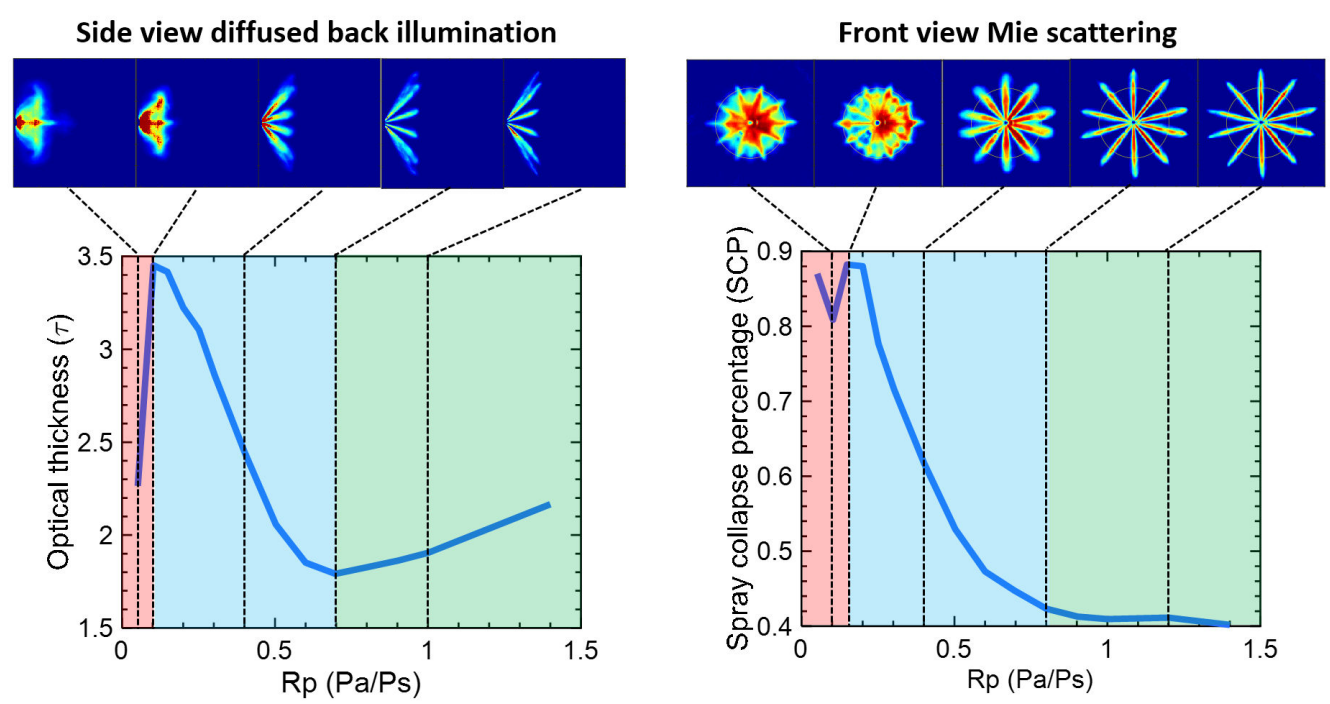

Spray collapse region Transitional region Non-flashing region

\section{Highlights}

- Simultaneous front view Mie-scattering and side view DBI images were captured to understand flash boiling.

- Collapse occurs in both radial and circumferential directions. 
- Two criteria for determination of spray regimes were proposed.

- Plume interaction and spray collapse criteria change with fuel temperature.

- Spray collapse depends on both ratio of ambient gas pressure to saturation vapor pressure $\left(R_{p}\right)$ and ambient pressure.

\section{Introduction}

In gasoline engines, flash boiling is a common phenomenon [1] that liquid fuel boils suddenly when it goes through a fast depressurization process to a pressure level lower than its saturated vapor pressure [2]. Flash boiling has the advantage of achieving proper atomization at a lower cost compared with increasing fuel injection pressure [3]. Droplet size has been reported $[4,5]$ to decrease when flash boiling occurs. But heavy flash boiling, which should be avoided, would cause spray collapse [3, 5], wall impingement [6] and reduces internal nozzle fuel flow rate [7]. Wang et al. [8] studied the closely coupled split injection strategy at flash boiling condition and concluded that it can shorten the spray penetration length and reduce the potential of spray impingement. Either to utilize or to prevent flash boiling, a better understanding of this complex process is required. Flash boiling and its accompanying spray collapse phenomenon have become an exciting topic among researchers recently.

Three commonly used variables to control the flash boiling intensity are the fuel temperature, ambient gas pressure, and saturation vapor pressure of the fuel. To study the influence of these factors on flash boiling and 
give general criteria, $R_{p}$ (ratio of ambient gas pressure to saturation vapor pressure) and $\Delta T$ (superheat degree) are the two mainly used parameters $[9,10,11,12]:$

$$
R_{p}=P_{a} / P_{s}
$$

$$
\Delta T=T_{f}-T_{s}
$$

where $P_{s}$ is the saturation pressure at fuel temperature $T_{f}, P_{a}$ is the ambient gas pressure, and $T_{s}$ is the saturation temperature of the fuel at the ambient gas pressure $P_{a}$.

Different indicators have been used to distinguish three different regimes including flare flash regime, transitional regime, and non-flashing regime. Some researchers have studied flash boiling using an 8-hole GDI injector with $60^{\circ}$ spray angle $[3,9,13]$. In their studies, penetration length, plume width, vapor quantity, droplet size and plume to plume distance (the two opposite plumes on the central cross section) were used as indicators to differentiate the regimes based on $R_{p}$. They classified the regimes as flare flashing regime $\left(R_{p}<0.3\right)$, the transitional regime $\left(0.3<R_{p}<1\right)$ and the non-flashing regime $\left(R_{p}>1\right)$. Lacey et al.[10] studied propane flashing sprays using ECN spray $\mathrm{G}$ injector and proposed a new indicator $D_{n}$, with nozzle geometry taken into consideration, and generalized the flashing criteria to be $D_{n} \geq$ $1, d_{t} / d_{\text {collapse }}<D_{n}<1, D_{n} \leq d_{t} / d_{\text {collapse }}$ from collapse regime to non-flash regime.

Spray collapse can happen both at non-flash boiling condition, and flash boiling condition for multi-hole GDI sprays. Guo et al.[14] explained them as jet induced collapse and condensation induced collapse, respectively. In both cases, plume to plume interaction is a vital precedent phenomenon. 
Wang et al. [15] studied the near nozzle single hole spray pattern under flash boiling conditions and observed increased cone angle and spray area when flash boiling occurs. Wu et al. [16] studied 1-hole, 2-holes, and 6-holes sprays at near nozzle region from flare flash to sub-cooled conditions. It was revealed that the single plume swells and multi-plume interactions occur when flash boiling phenomenon takes place. Heldmann et al. [17] studied the separate single plume of the 5-hole injector and interaction between single plumes from two different 5-hole injectors. These above mentioned single plume and multi-plume interaction studies help to understand the spray pattern change in a multi-hole GDI injector under flash boiling conditions. Investigation of plume interaction is mandatory for better understanding of the complex collapse process.

Most reported experimental work on spray collapse phenomenon were through side view and volume illumination (backlight imaging) [11, 18, 19, 20, 21, 22, 23, 24], Mie-scattering [10, 25, 26] or schlieren [10, 12, 22, 25]), which has the advantage of capturing transient spray included cone angle or spray width and reporting directly whether spray collapse happens or not. But it inevitably has the drawback of overlapping of plumes and is not capable of illuminating inner structure of spray and demonstrating plume to plume interaction. It's challenging to explain that merge of plumes on the image is due to plume interactions or due to overlapping along the line of sight, especially when the number of holes is relatively high.

Few works $[9,13,18,27]$ have been reported with laser sheet illumination to show the cross-sectional view of the spray (either through central plane showing spray inner structure or perpendicular to injector axis show- 
ing plumes cross section at a fixed distance from the nozzle). However, a very recent publication has reported laser sheet imaging for a 2-hole nozzle [28] showing plume to plume interaction. Again the setback of these laser sheet based imaging techniques is that it is very challenging to capture the interaction between adjacent plumes for a real multi-hole GDI injector.

For multi-hole injector sprays, Mie-scattering images taken from the front view (ahead of spray cone) can be an attractive choice to visualize the transition from segregated plumes to connected plumes or collapsed plumes, without the issue of overlapping between plumes. While minimal work has been done with this method on plume to plume interaction under spray collapsing conditions and particularly direct simultaneous comparison between side view and front view images, have not been done so far for flashing sprays. Sphicas et al. [21] have implemented front view Mie-scattering in the study of spray collapse at non-flashing conditions for ECN spray-G. Mojtabi [29] studied plume to plume interaction under flash boiling conditions on GDI injectors solely from front view. Gutierrez [30] studied ECN spray-G morphology in a single cylinder engine under flash boiling conditions using front view Mie-scattering.

Considering minimal work that has been done using front view imaging for plume interaction studies, this work bridges the gap by visualizing the spray from both the side view (DBI) and the front view (Mie-scattering) simultaneously with two high-speed cameras. It gives a clear image showing how the transient plume to plume interaction is related to the collapsing phenomenon usually observed from the side. Two new criteria based on front view Mie-scattering and side view DBI images were proposed to segregate 
spray behavior into strong collapse regime, transitional regime, and nonflashing regime. These criteria were compared with widely used conventional indicators based on liquid penetration length and spray width.

\section{Experimental setup and diagnostics}

Experiments were carried out in KAUST Spray Lab. Figure 1 (a) shows the setup alignment for simultaneous DBI and Mie-scattering imaging techniques. The chamber used in this study is capable of handling gas pressure from the sub-atmospheric condition to 10 bar absolute pressure. The large chamber volume of 27 liters benefits the study of spray at low ambient gas density conditions, like flash boiling, without encountering the problem of wall interactions. A 10-hole GDI injector was mounted horizontally on one side, and optical windows on the other three sides allow the possibility to run diffused back illumination (DBI) and Mie-scattering at the same time. Two high-speed cameras (Photron SA-X2) were mounted facing towards the injector tip and from side for Mie-scattering and DBI imaging, respectively. A high power LED was used in a high-speed repetitive pulse mode to ensure sufficient Mie-scattering intensity. At the same time, optimized aperture and neutral density (ND) filter were used for DBI imaging to avoid saturation of the camera. Two cameras were synchronized at $40 \mathrm{kfps}$ frame rate to capture the same spray from different perspectives at a sufficiently high temporal resolution to obtain enough information of flashing sprays. Resolution of DBI and Mie-scattering images are $0.22 \mathrm{~mm} /$ pixel $(512 \times 512)$ and $0.28 \mathrm{~mm} /$ pixel $(512 \times 552)$, respectively.

An Aramco customized high-pressure multi-hole injector was studied in 
this work. The injector was fixed in a custom-made fixture, which has an internal channel connected with a heat exchanger, shown in Figure 1(b). The internal volume of the fixture covers injector head thus that fuel temperature can be controlled. Figure 1(c) shows the orientation of 10 nozzle holes, each of diameter $\phi 165 \mu \mathrm{m}$. National Instruments Direct Injector Driver System (NI DIDS-2003) was used to drive the injector. The injector excitation duration was fixed at $1 \mathrm{~ms}$ throughout this study.

\section{Experimental conditions}

Table 1 shows the experimental conditions used for this study. In this work, a single component fuel iso-octane was studied as a surrogate of complex multi-component gasoline fuels. The injection pressure was fixed at 100 bar and excitation duration of $1 \mathrm{~ms}$. Ambient gas temperature was kept at room temperature. Fuel temperature and ambient gas pressure are the two variables examined in this study. Fuel temperature was varied from $60{ }^{\circ} \mathrm{C}$ to $120^{\circ} \mathrm{C}$. Since $R_{p}$ is of more interest rather than the absolute ambient gas pressure, $R_{p}$ was varied in 15 levels $(0.05-1.4)$ for each fuel temperature. As saturation vapor pressure varies with fuel temperature, the absolute ambient gas pressure was determined based on $R_{p}$ and saturation vapor pressure accordingly as shown in Table 2. Iso-octane saturation vapor pressure was obtained using Antoine's equation (Eq. 3) from the NIST website [31].

$$
\log _{10}(P)=A-\frac{B}{T+C}
$$

where, $\mathrm{P}$ is the vapor pressure in bar and $\mathrm{T}$ is the fuel temperature in $\mathrm{K}$.

According to $\mathrm{Xu}$ et al. [3], $R_{p}$ of 1 is the starting point of the transitional regime for their injector and fuel combination. Therefore in this study, $R_{p}$ 
data points are refined below 1 and further refined when $R_{p} \leq 0.3$ to capture the change in plume interactions. Experimental conditions and iso-octane vapor pressure curve are shown in Figure 2. Each case was repeated five times.

\section{Results and discussions}

\subsection{Comparison of instantaneous and averaged spray images}

The average image from 5 repeats is compared against the five individual runs in Figure 3. The selected case is for a fuel temperature of $120^{\circ} \mathrm{C}$ which has a low $R_{p}(0.05)$ and spray shows an extreme collapse. DBI images show that a central jet is formed and penetrates much longer than the surrounding regions. The simultaneous Mie-scattering image confirms that this jet is indeed along the center line by showing an entirely white area in the center. In each instantaneous events, more detailed small scale features could be seen from the images, while the averaged image would smooth these features. However, the overall spray morphology and large scale features have remained the same even after the averaging process. Since all Mie-scattering and DBI videos are taken simultaneously for the same spray event, the averaged image from five repeats for the two methods would still be comparable. Thus image post-processing and criteria definition hereafter will be based on the averaged images.

\subsection{Plume interactions}

Figure 4 shows the comparison of spray morphology at different $R_{p}$ for a fuel temperature of $120^{\circ} \mathrm{C}$ at a time after the start of injection (Time aSOI) 
of $0.3 \mathrm{~ms}$. The front view Mie-scattering images can reveal that plume interaction does not exist at conditions at $R_{p} \geq 0.6$. However, it is difficult to come to this conclusion from the DBI images due to the overlapping of plumes along the line of sight. Both methods qualitatively show that plumes become thicker when $R_{p}$ decreases. When $R_{p}$ decreased to 0.5 , Mie-scattering image shows that plume to plume interaction starts between the two plumes at the horizontal plane (these two plumes have a smaller gap than that between other plumes). This interaction becomes stronger when $R_{p}$ is further decreased to 0.2 , where plume interaction between other adjacent plumes also begins. Plumes shown in DBI images become connected. This condition can be regarded as the starting point of spray collapse due to flashing conditions. At $R_{p}=0.15$, newly concentrated plumes are formed in the region between the original plumes and co-exist with them. At $R_{p}=0.1,0.05$, the plumes no more exist at its original positions. Instead, newly concentrated plumes caused by plume interaction are observed.

Figure $5 \mathrm{a}$ and $\mathrm{b}$ shows the comparison of two cases $\left(R_{p}=0.05\right.$ and 0.4$)$ where plume directions are different. The intensity in the Mie-scattering images along the predefined circle (Figure 6) clearly shows the shift of plume orientation when $R_{p}$ decreases from 0.4 to 0.15 . The corresponding Miescattering images can refer to 4 . With a $R_{p}$ greater than 0.2 , the original plumes are clear and intensity peaks fall on the original plume direction. However in the case of $R_{p}=0.15$, main peaks are found between the original plumes and small intensity peaks coexist at the location of original plumes. This is the case where new concentrated plumes start to form. At $R_{p}=0.1$, the original plumes start fading away and disappear at $R_{p}=0.05$. Through 
Figure 4 and Figure 6, how the plume interaction and spray collapse develop when $R_{p}$ decreases are clearly elucidated.

The collapsing phenomenon observed from the Mie-scattering images is due to plume expansion and the adjacent two plumes interaction. The adjacent two plumes collapses in the circumferential direction and forms a new concentrated jet in between. However, the 10 plumes also experience a radial collapse, which should be highlighted. In the lowest $R_{p}$ case, a central jet was observed from DBI images. All the plumes expand due to flash boiling and interact along injector axis. As a result of 10-plumes interaction and collapse in the radial direction, a new concentrated jet was formed along the injector center line. The location of this central jet was confirmed by the Mie-scattering image since it is white within the center of the spray hiding the nozzle behind. Similar phenomenon was observed previously by Schulz and Beyrau [32] using a 6-hole GDI injector.

\subsection{Effect of fuel temperature}

Figure 7 shows the comparison of front view Mie-scattering images at Time aSOI of $0.3 \mathrm{~ms}$ for all the cases. It shows very similar plume interaction behavior for conditions with the same $R_{p}$. However, a slight difference still can be found for each row in regards to plume width, length, and plume interaction intensity. Under all the fuel temperatures from $60^{\circ} \mathrm{C}$ to $120^{\circ} \mathrm{C}$, all adjacent plumes start interacting at around $R_{p}=0.2$, but the intensity of interaction is different (At a lower fuel temperature, plume interaction looks more complete than at a higher fuel temperature). Figure 8 shows the corresponding side view DBI images. Similar spray patterns are found at the same $R_{p}$ but different fuel temperatures. Again, for the same $R_{p}$, 
plume merging looks more obvious at lower fuel temperatures. Qualitative comparison by looking at the Mie-scattering and DBI images is not very conclusive. Instead, a quantitative description is needed for the justification of the spray collapse phenomenon. Two new indicators, the spray collapse percentage based on the front view Mie-scattering image, and the optical thickness based on the side view DBI imaging are proposed and will be discussed in detail in the following sections.

\subsection{Spray collapse criteria}

\subsubsection{Definition of spray collapse percentage (SCP) criterion}

Figure 9 shows the spray morphology at (a) $R_{p}=0.05$ and (b) $R_{p}=1.4$ for fuel temperature of $T_{\text {fuel }}=120^{\circ} \mathrm{C}$ with detected spray boundary from the front view Mie-scattering images. The first criteria introduced in this study is based on the Mie-scattering front view images referred to as 'spray collapse percentage (SCP)'. Spray collapse percentage (SCP) is defined as the ratio of the spray area inside a pre-defined circle to the area of the pre-defines circle, as shown in Eq. 4.

$$
S C P=S_{\text {spray }} / S_{\text {circle }}
$$

where, $S_{\text {spray }}$ is the area of spray region calculated from the binary image within the pre-defined circle of radius $r_{0}$ and $S_{\text {circle }}$ is the area of the predefined circle given by $\pi r_{0}{ }^{2}$. The $r_{0}$ is calculated as the radius of the circle which has an equal area as the whole spray region defined based on the lowest $R_{p}$ case for a specific fuel temperature.

At non-flashing conditions, SCP will keep unchanged at a low level as expected. When flash boiling happens, the plume will expand, and SCP will 
increase as a result. When $R_{p}$ decreases to a low-value collapse of the spray increases, and the region in the center is fully occupied by spray and SCP approaches to 1 . Therefore, the value of SCP would give information about spray collapse intensity. The change of SCP with $R_{p}$ is shown in Figure 9 (c). The clear turning point can be found on the curve at around $R_{p}=0.8$ and $R_{p}=0.2$, between which corresponds to the transitional regime. Thus $\mathrm{SCP}$ is a good candidate criterion for determination of collapsing regime, transitional regime and non-flashing regime.

Flare flash is an indicator on the intensity of phase change. However, the criteria defined in this work are based on spray morphology (spray collapsing phenomenon), which depends not only on flash boiling intensity but also on the nozzle geometry (the original gap between adjacent plumes). An injector with much-separated nozzle holes may experience flare flash under the extremely super-heated condition for all individual plumes, but spray collapse may not necessarily be there. Thus a spray shape based criterion would not be accurate to name a regime as flare flash regime. Therefore in this work, the three distinct regimes identified by the new criterion will be designated as collapsing regime, transitional regime, and non-flashing regime.

\subsubsection{Definition of optical thickness $(\tau)$ criterion}

For the side view DBI images, a new criterion based on optical thickness is used. The optical thickness $(\tau)$ is defined by Eq.5

$$
I / I_{0}=e^{-\tau}
$$

where $I$ is the attenuated light intensity and $I_{0}$ is the original light intensity. In this study, the average optical thickness is calculated from a DBI 
image on the binarized spray region. Since flash boiling and spray collapse phenomena affect the atomization quality and droplet spatial distribution, the optical thickness distribution would also be changed with $R_{p}$.

Figure 10(a) and (b) shows the optical thickness distribution for $R_{p}=$ 0.05 and $R_{p}=1.4$, respectively. For non-flashing spray with $R_{p}=1.4$, the optically dense region is the plume liquid core region. When spray collapse happens, due to plume interaction, the original gap between adjacent plumes will be occupied with liquid as well. Thus the local optical thickness distribution can change dramatically. By averaging the optical thickness over the entire spray region defined by the green boundary line, its relationship with $R_{p}$ can be plotted as Figure 10(c). The two clear turning points on this curve can be used to distinguish the three different spray regimes.

\subsection{Sensitivity of spray collapse percentage (SCP) based criterion}

\subsubsection{Binarization threshold}

The threshold used for image binarization can affect $S_{\text {spray }}$ as well as the equivalent $r_{0}$, thus affects SCP. Figure 11(a) shows the auto-calculated threshold value based on Otsu's method for all cases at $T_{\text {fuel }}=120^{\circ} \mathrm{C}$. The variance of the threshold value between cases is less than 20\%, and the averaged threshold value is 0.3075 . Fixed thresholds at the averaged threshold value and $\pm 10 \%$, and $\pm 20 \%$ are examined to study the influence of the threshold value on this criterion. Figure 11(b) shows the SCP trend obtained with the different threshold value. It is clear that threshold value can affect SCP value quantitatively, same like other indicators (penetration length, spray width). But the trend remains the same, and the turning points which distinguishes different regimes on the curve stay unchanged. 
Thus hereafter, auto-calculated threshold value based on Otsu's method will be used for each image.

\subsubsection{Pre-defined circle radius}

The circle radius should not exceed the spray region to avoid pure black region on the images. A circle radius $r_{0}$ calculated based on the lowest $R_{p}$ case at a certain fuel temperature is a good selection as the upper limit and as a reference. The sensitivity of SCP criterion on circle radius $r$ is evaluated based on the different values of $r$ such as $r_{0}, 0.8 r_{0}, 0.6 r_{0}$ and $0.4 r_{0}$. Figure 12(a) shows that the SCP trend remains similar when $r$ changes from $0.4 r_{0}$ to $r_{0}$, but the curves contrast changed a lot. When the $r$ is selected to be too small, the minimum SCP at non-flashing regime would still be high thus reduced the contrast of the curve. This behavior is because of the high white percentage in the near-nozzle region. To avoid the influence of this high white percentage near the nozzle, the pre-defined circle radius should be large enough. Therefore, the value of $r \geq 0.6 r_{0}$ could be a good choice since it clearly shows the starting point of the spray collapse regime. However, throughout this study, the value of $r_{0}$ is used for analysis.

\subsubsection{Time instant}

Figure 12(b) shows that during the early injection period, penetration length is short and the influence of near nozzle high white percentage will affect the estimation of criterion. Spray morphology at late injection period is a better choice for criterion determination since the spray is fully developed. The SCP at $0.3 \mathrm{~ms}$ to $0.9 \mathrm{~ms}$ indicate that it is a very consistent criterion. Considering that starting from $0.5 \mathrm{~ms}$ the spray on DBI images 
will be exceeded the optical limit of the window, therefore hereafter, $0.3 \mathrm{~ms}$ aSOI will be used for further comparison among different criteria.

\subsection{Sensitivity of optical thickness $(\tau)$ based criterion}

\subsubsection{Binarization threshold}

Firstly Otsu's method is used for image binarization $\left(T_{\text {fuel }}=120^{\circ} \mathrm{C}\right.$, Time aSOI $=0.3 \mathrm{~ms}$ ). Figure 13(a) shows the threshold values for all cases with Otsu's method. And then the mean value of all these cases and $\pm 10 \%$, and \pm $20 \%$ of this value are compared. Figure 13(b) shows that the turning point is consistent for these values of the binarization threshold. Thus the averaged optical thickness based criterion is not sensitive to the threshold as long as the same method of threshold selection is applied to all cases.

\subsubsection{Time instant}

Time instant selection is another factor that needs to be considered for the generalization of the optical thickness based criterion. For the calculation of averaged optical thickness based on the whole spray region, it would be better if the spray is entirely inside optical window access. Thus an earlier instant timing is a better choice. At $0.5 \mathrm{~ms}$ aSOI, the spray plumes already reached window edge. Therefore, time aSOI from $0.1 \mathrm{~ms}$ to $0.4 \mathrm{~ms}$ were considered for the sensitivity analysis (Otsu's threshold, $T_{\text {fuel }}=120^{\circ} \mathrm{C}$ ) as shown in figure 13(c). It can be seen that the turning point on the curves to distinguish different regimes is consistent with different time instant. Thus $0.3 \mathrm{~ms}$ aSOI was selected for this criterion, and also it was kept consistent with the time instant selected for SCP criteria based on Mie-scattering images. 


\subsection{Comparison between different criteria}

Based on the sensitivity analysis of SCP based criterion, Otsu's threshold method, $r_{0}$ for circle radius and $0.3 \mathrm{~ms}$ aSOI for Mie-scattering spray images will be used. Figure 14(a) indicates that transitional regime starts at around $R_{p}=0.7 \sim 0.8$ and spray collapse regime starts at around $R_{p}=0.15 \sim 0.2$.

The critical $R_{p}$ value for the start of the transitional regime looks shifting towards low $R_{p}$ end when fuel temperature increases. To further confirm, the derivative of SCP is calculated with respect to $R_{p}$ and shown in Figure 14(b). If for example a low absolute value of the derivative is regarded as the turning point on the SCP curve, it shows that higher fuel temperature will reach this turning point at lower $R_{p}$ value. It means that increased fuel temperature requires a lower $R_{p}$ to achieve the same effect of plume expansion.

Since the plume interaction is due to the swelling of plumes at flash boiling condition, the plume angle can be another good indicator for criterion determination. Here the plume angle is defined inside the $r_{0}$ circle as well. Each plume was separated by segmentation (radius $=r_{0}$, Figure 15) and then binarized with Otsu's method. The area of the segmented plume and the plume penetration length can then be used to calculate the plume angle with the assumption that the segmented plume is sector-shaped. Average of the 10 plume angles is shown in Figure 14(c) for different fuel temperatures and $R_{p}$. It should be noted that when plume interaction starts, this definition of plume angle will fail. Thus it is only used for the regime at $R_{p} \geq 0.4$. So it can be used for the determination of the transitional regime and nonflashing regime, but not suitable for spray collapse regime. It indicates that transitional regime starts from $R_{p}$ around 0.9. Meanwhile, it clearly shows 
that at same $R_{p}$, higher fuel temperature has smaller plume cone angle, which weakens the plume interaction.

In this study, the average optical thickness is calculated from a DBI image based on the binarized spray region where the optical thickness is greater than Otsu's threshold value. Using optical thickness as an indicator gives the obvious trend shown in Figure 16(a). Both transitional regime and spray collapse regime starting point are shifted slightly towards low $R_{p}$ side when $T_{\text {fuel }}$ increases, from 0.9 to 0.6 and 0.2 to 0.15 , respectively. This is consistent with the Mie-scattering images shown in Figure 7 . With same $R_{p}, T_{\text {fuel }}=$ $120^{\circ} \mathrm{C}$ has a thinner spray plume and less plume interaction than $T_{\text {fuel }}=$ $60^{\circ} \mathrm{C}$. This shifting could also be noted from Mie-scattering image based criteria shown in Figure 14.

Penetration length and spray width from the side view DBI images are commonly used criteria in the literature to describe the change in spray morphology due to collapse $[3,9,13]$. They were defined as shown in Figure 17. Figure 16(b) and (c) shows the comparison of penetration length, and spray width with corresponding $R_{p}$, respectively. The penetration length and spray width are characterized at time instant of $0.3 \mathrm{~ms}$ aSOI to avoid spray penetration exceeding the window limit. Liquid penetration length and spray width both show a turning point at around $R_{p}=0.1 \sim 0.2$, which is due to spray collapse phenomenon. But between the transitional regime and non-flashing regime, these two indicators are not capable of giving a distinct criterion.

In general, both transitional and spray collapse criteria are based on spray morphology, which is not only affected by flash boiling intensity $\left(R_{p}\right)$ but also 
by the ambient gas pressure. Thus higher fuel temperature, which simultaneously has higher ambient pressure for a specific $R_{p}$ will make it more difficult for plumes to expand, interact with each other and then collapse. Thus the starting points of transitional regime and spray collapse regime are shifting towards a low $R_{p}$ end when fuel temperature increases.

Penetration length is defined as the farthest penetrated point on spray boundary in the axial direction, and spray width is defined as the distance between two farthest points on the spray boundary in the radial direction (Figure 17). Both methods are defined on the extreme points on the spray boundary. While these points are susceptible to the threshold or it may tremendously change to another far away position when its original location is diluted which means it exhibits high positional dependency and missed by the boundary detection algorithm. Thus the trend based on these two indicators will have considerable variation and make it challenging to define the distinct regimes. The spray collapse percentage and averaged optical thickness are based on the entire spray region. Therefore, these two indicators are less sensitive to threshold selection and shot to shot variations as already explained in previous sections. Thus these two indicators can show a very consistent and clear trends with the change of $R_{p}$ and helps in the determination of distinct spray regimes.

\section{Conclusions}

In this study, the simultaneous side view DBI imaging and front view Mie-scattering imaging were employed to study the spray collapse in flash boiling conditions. The following conclusions can be drawn from this study. 
- Simultaneous side view DBI and front view Mie-scattering enable correlating plume interaction to spray collapse phenomenon and apparently show when the plume to plume interaction starts. This method could be a good way to study flash boiling and spray collapse phenomenon.

- At extremely low $R_{p}(0.05)$ conditions, a long central jet was observed on DBI images, and this was confirmed by the entirely white area on Mie-scattering images. This phenomenon is due to the 10-plumes interaction and the radial collapse. The very different spray morphology from other conditions was also reflected in the outwardly moving backward spray periphery during the entire injection duration.

- Two new indicators, spray collapse percentage (SCP) based on Miescattering imaging, and optical thickness based on DBI imaging were proposed and used as the criteria for determination of spray collapse, transitional, and non-flashing regime.

- SCP and optical thickness criteria were compared with criteria determined from other indicators like plume angle, spray penetration length and spray width. Optical thickness from side view DBI images and SCP from front view Mie-scattering images are two consistent and effective indicators for the determination of spray regimes.

\section{Acknowledgement}

This work was sponsored by Saudi Aramco under the FUELCOM II program and by King Abdullah University of Science and Technology. 


\section{References}

[1] Krämer, M., Kull, E., Wensing, M.. Flashboiling-induced targeting changes in gasoline direct injection sprays. International Journal of Engine Research 2016;17(1):97-107. doi: \bibinfo\{doi\}\{10.1177/ $1468087415604763\}$.

[2] Baumgarten, C.. Mixture formation in internal combustion engines. Springer Science \& Business Media; 2006.

[3] Xu, M., Zhang, Y., Zeng, W., Zhang, G., Zhang, M.. Flash Boiling: Easy and Better Way to Generate Ideal Sprays than the High Injection Pressure. Tech. Rep. 1; 2013. doi: \bibinfo $\{$ doi $\}\{10.2307 / 26272805\}$. URL https : //www . jstor .org/stable/26272805.

[4] Jiang, C., Parker, M.C., Helie, J., Spencer, A., Garner, C.P., Wigley, G.. Impact of gasoline direct injection fuel injector hole geometry on spray characteristics under flash boiling and ambient conditions. Fuel $2019 ; 241: 71-82$.

[5] Guo, H., Ma, X., Li, Y., Liang, S., Wang, Z., Xu, H., et al. Effect of flash boiling on microscopic and macroscopic spray characteristics in optical GDI engine. Fuel 2017;190:79-89. URL https://linkinghub. elsevier.com/retrieve/pii/S0016236116311449https://www . sciencedirect.com/science/article/pii/S0016236116311449.

[6] Wang, Z., Li, Y., Guo, H., Wang, C., Xu, H.. Microscopic and macroscopic characterization of spray impingement under flash boiling condi- 
tions with the application of split injection strategy. Fuel 2018;212:315325.

[7] Reitz, R.D.. A Photographic Study of Flash-Boiling Atomization. Aerosol Science and Technology 1990;12(3):561-569. doi: \bibinfo\{doi\} $\{10.1080 / 02786829008959370\}$.

[8] Wang, Z., Jiang, C., Xu, H., Badawy, T., Wang, B., Jiang, Y.. The influence of flash boiling conditions on spray characteristics with closely coupled split injection strategy. Applied energy 2017;187:523-533.

[9] Zeng, W., Xu, M., Zhang, G., Zhang, Y., Cleary, D.J.. Atomization and vaporization for flash-boiling multihole sprays with alcohol fuels. Fuel 2012;95:287-297. doi: \bibinfo\{doi\}\{10.1016/j.fuel.2011.08.048\}. URL http://linkinghub. elsevier.com/retrieve/pii/S0016236111005229https://www. sciencedirect.com/science/article/pii/S0016236111005229.

[10] Lacey, J., Poursadegh, F., Brear, M.J., Gordon, R., Petersen, P., Lakey, C., et al. Generalizing the behavior of flashboiling, plume interaction and spray collapse for multi-hole, direct injection. Fuel 2017;200:345-356. doi: \bibinfo\{doi $\}\{10.1016 /$ j.fuel.2017. 03.057\}. URL https://www.sciencedirect.com/science/article/ $\mathrm{pii/S0016236117303344.}$

[11] Li, Y., Guo, H., Ma, X., Qi, Y., Wang, Z., Xu, H., et al. Morphology analysis on multi-jet flash-boiling sprays under wide ambient pressures. Fuel 2018;211:38-47. doi: 
$\backslash$ bibinfo\{doi\}\{10.1016/j.fuel.2017.08.082\}. URL https://linkinghub. elsevier.com/retrieve/pii/S0016236117310670https://www . sciencedirect.com/science/article/pii/S0016236117310670.

[12] Araneo, L., Donde', R.. Flash boiling in a multihole GDI injector - Effects of the fuel distillation curve. Fuel 2017;191:500-510. doi: \bibinfo\{doi\}\{10.1016/j.fuel.2016.11.104\}. URL https://www.sciencedirect.com/science/article/ pii/S0016236116312133https://www.sciencedirect.com/ science/article/pii/S0016236116312133?via\{\%\}3Dihubhttps : //linkinghub.elsevier.com/retrieve/pii/S0016236116312133.

[13] Zhang, G., Xu, M., Zhang, Y., Zeng, W.. Quantitative Measurements of Liquid and Vapor Distributions in Flash Boiling Fuel Sprays using Planar Laser Induced Exciplex Technique. 2011. doi: bibinfo $\{$ doi $\}\{10$. 4271/2011-01-1879\}. URL http://papers.sae.org/2011-01-1879/.

[14] Guo, H., Ding, H., Li, Y., Ma, X., Wang, Z., Xu, H., et al. Comparison of spray collapses at elevated ambient pressure and flash boiling conditions using multi-hole gasoline direct injector. Fuel 2017;199:125-134. doi: \bibinfo\{doi\}\{10.1016/J.FUEL.2017.02.071\}. URL https://www.sciencedirect.com/science/article/pii/ S0016236117302247https://linkinghub.elsevier.com/retrieve/ pii/S0016236117302247.

[15] Wang, Z., Wang, B., Jiang, C., Xu, H., Badawy, T.. Microscopic characterization of isooctane spray in the near field under flash boiling condition. Applied energy 2016;180:598-606. 
[16] Wu, S., Xu, M., Hung, D.L., Li, T., Pan, H.. Near-nozzle spray and spray collapse characteristics of spark-ignition direct-injection fuel injectors under sub-cooled and superheated conditions. Fuel 2016;183:322334. doi: \bibinfo\{doi\}\{10.1016/j.fuel.2016.06.080\}. URL https:// linkinghub.elsevier.com/retrieve/pii/S0016236116305397.

[17] Heldmann, M., Bornschlegel, S., Wensing, M.. Investigation of jetto-jet interaction in sprays for disi engines. Tech. Rep.; SAE Technical Paper; 2015.

[18] Wu, S., Yang, S., Wooldridge, M., Xu, M.. Experimental study of the spray collapse process of multi-hole gasoline fuel injection at flash boiling conditions. Fuel 2019;242:109-123.

[19] Li, Y., Guo, H., Fei, S., Ma, X., Zhang, Z., Chen, L., et al. An exploration on collapse mechanism of multi-jet flash-boiling sprays. Applied Thermal Engineering 2018;134:20-28. doi: \bibinfo\{doi\} \{10.1016/J.APPLTHERMALENG.2018.01.102\}. URL https://www . sciencedirect.com/science/article/pii/S1359431117331423.

[20] Li, Y., Guo, H., Zhou, Z., Zhang, Z., Ma, X., Chen, L.. Spray morphology transformation of propane, n-hexane and iso-octane under flash-boiling conditions. Fuel 2019;236:677-685. doi: \bibinfo $\{$ doi $\}\{10$. 1016/J.FUEL.2018.08.160\}. URL https://www.sciencedirect.com/ science/article/pii/S0016236118315308.

[21] Sphicas, P., Pickett, L.M., Skeen, S.A., Frank, J.H.. Inter-plume 
aerodynamics for gasoline spray collapse. International Journal of Engine Research 2018;19(10):1048-1067.

[22] Payri, R., Salvador, F.J., Martí-Aldaraví, P., Vaquerizo, D.. ECN Spray G external spray visualization and spray collapse description through penetration and morphology analysis. Applied Thermal Engineering 2017;112:304-316. doi:\bibinfo\{doi\} \{10.1016/J.APPLTHERMALENG.2016.10.023\}. URL https://www . sciencedirect.com/science/article/pii/S1359431116322128.

[23] Aleiferis, P., van Romunde, Z.. An analysis of spray development with iso-octane, n-pentane, gasoline, ethanol and n-butanol from a multi-hole injector under hot fuel conditions. Fuel 2013;105:143168. URL http://linkinghub.elsevier.com/retrieve/pii/ S0016236112005935https://wWw.sciencedirect.com/science/ article/pii/S0016236112005935.

[24] Guo, H., Wang, B., Li, Y., Xu, H., Wu, Z.. Characterizing external flashing jet from single-hole GDI injector. International Journal of Heat and Mass Transfer 2018;121:924-932. doi: \bibinfo\{doi\}\{10.1016/J.IJHEATMASSTRANSFER.2018.01.042\}. URL https://www.sciencedirect.com/science/article/pii/ S0017931017330971https://linkinghub.elsevier.com/retrieve/ pii/S0017931017330971.

[25] Kale, R., Banerjee, R.. Experimental investigation on GDI spray behavior of isooctane and alcohols at elevated pressure and temperature conditions. Fuel 2019;236:1-12. doi: \bibinfo\{doi\}\{10.1016/j.fuel. 
2018.08.153\}. URL https://linkinghub.elsevier.com/retrieve/ pii/S0016236118315230.

[26] Montanaro, A., Allocca, L.. Flash boiling evidences of a multi-hole gdi spray under engine conditions by mie-scattering measurements. Tech. Rep.; 2015.

[27] Li, T., Dong, X., Hung, D.L., Li, X., Xu, M.. Analysis of evaporation characteristics and heat transfer for flash-boiling sprays. International Journal of Heat and Mass Transfer 2018;127:244-254.

[28] Xu, Q., Pan, H., Gao, Y., Li, X., Xu, M.. Investigation of twohole flash-boiling plume-to-plume interaction and its impact on spray collapse. International Journal of Heat and Mass Transfer 2019;138:608619 .

[29] Mojtabi, M., Wigley, G., Helie, J.. The effect of flash boiling on the atomization performance of gasoline direct injection multistream injectors. Atomization and Sprays 2014;24(6).

[30] Gutierrez, L., Mansfield, A.B., Fatouraie, M., Assanis, D., Singh, R., Lacey, J., et al. Effects of engine speed on spray behaviors of the engine combustion network "spray g" gasoline injector. Tech. Rep.; SAE Technical Paper; 2018.

[31] Willingham, C.B., Taylor, W.J., Pignocco, J.M., Rossini, F.D.. Vapor pressures and boiling points of some paraffin, alkylcyclopentane, alkylcyclohexane, and alkylbenzene hydrocarbons. Journal of Research of the National Bureau of Standards 1945;35(3):219-244. 
575 [32] Schulz, F., Beyrau, F.. The influence of flash-boiling on spray-targeting and fuel film formation. Fuel 2017;208:587 - 594. doi:\bibinfo\{doi\} \{10.1016/j.fuel.2017.07.047\}. URL http://www.sciencedirect.com/ science/article/pii/S001623611730902X.

[33] Otsu, N.. A threshold selection method from gray-level histograms. IEEE transactions on systems, man, and cybernetics 1979;9(1):62-66. 
Table 1: Experimental details

\begin{tabular}{|c|c|c|}
\hline Item & Unit & Value \\
\hline Injector & - & 10-hole, $165 \mu \mathrm{m}, 110^{\circ}$ \\
\hline Fuel & - & Iso-octane \\
\hline Injection pressure & bar & 100 \\
\hline Injection duration & $\mathrm{ms}$ & 1 \\
\hline Ambient gas temperature & ${ }^{\circ} \mathrm{C}$ & 23 \\
\hline
\end{tabular}

Table 2: Fuel temperature and ambient gas pressure

\begin{tabular}{|c|c|c|c|c|c|c|c|c|c|c|c|c|c|c|c|}
\hline$T_{\text {fuel }}\left({ }^{\circ} \mathrm{C}\right)$ & \multicolumn{10}{|c|}{$P_{\text {amb }}(\mathrm{kPa})$} \\
\hline 60 & - & - & 4 & 6 & 7 & 8 & 11 & 14 & 17 & 20 & 22 & 25 & 28 & 34 & 39 \\
\hline 75 & - & 5 & 7 & 10 & 12 & 14 & 19 & 24 & 29 & 34 & 38 & 43 & 48 & 58 & 67 \\
\hline 90 & 4 & 8 & 12 & 15 & 19 & 23 & 31 & 39 & 46 & 54 & 62 & 69 & 77 & 92 & 108 \\
\hline 105 & 6 & 12 & 18 & 24 & 30 & 35 & 47 & 59 & 71 & 83 & 94 & 106 & 118 & 142 & 165 \\
\hline 120 & 9 & 18 & 26 & 35 & 44 & 53 & 70 & 88 & 105 & 122 & 140 & 158 & 175 & 210 & 245 \\
\hline \multicolumn{110}{|c|}{$R_{p}=P_{a} / P_{s}$} \\
\hline & 0.05 & 0.1 & 0.15 & 0.2 & 0.25 & 0.3 & 0.4 & 0.5 & 0.6 & 0.7 & 0.8 & 0.9 & 1 & 1.2 & 1.4 \\
\hline
\end{tabular}

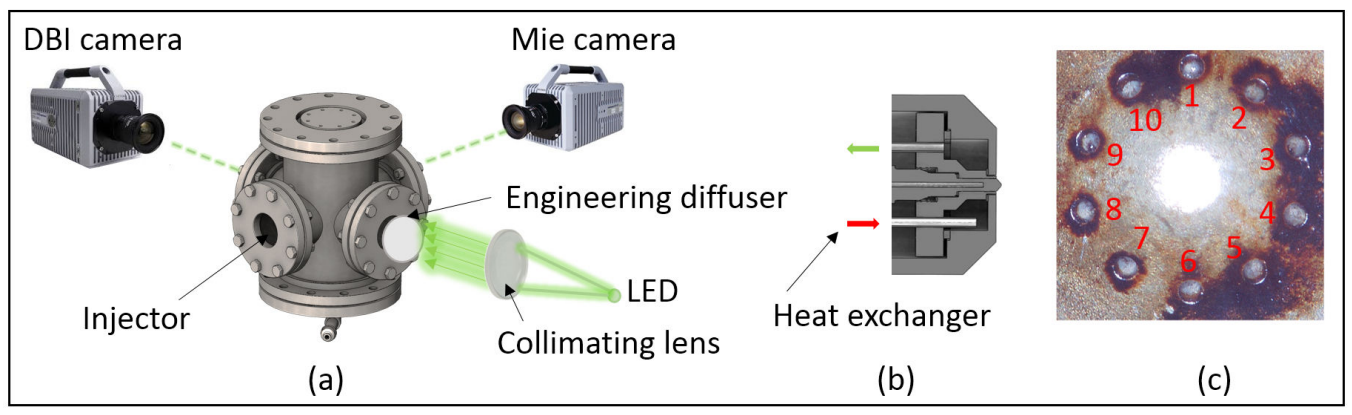

Figure 1: (a) Optical alignment for DBI and Mie-scattering; (b) Fuel temperature control; (c) Nozzle hole orientation 


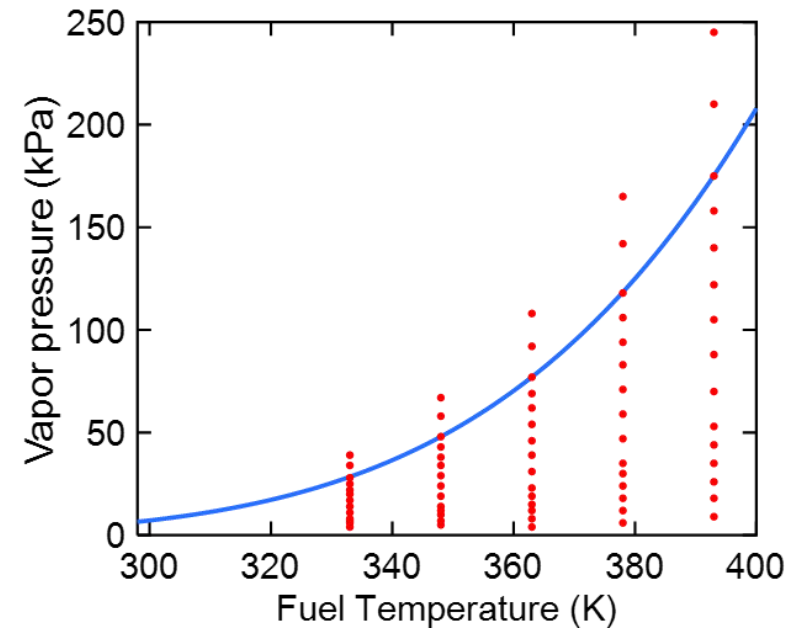

Figure 2: Iso-octane saturation vapor pressure and experiment conditions

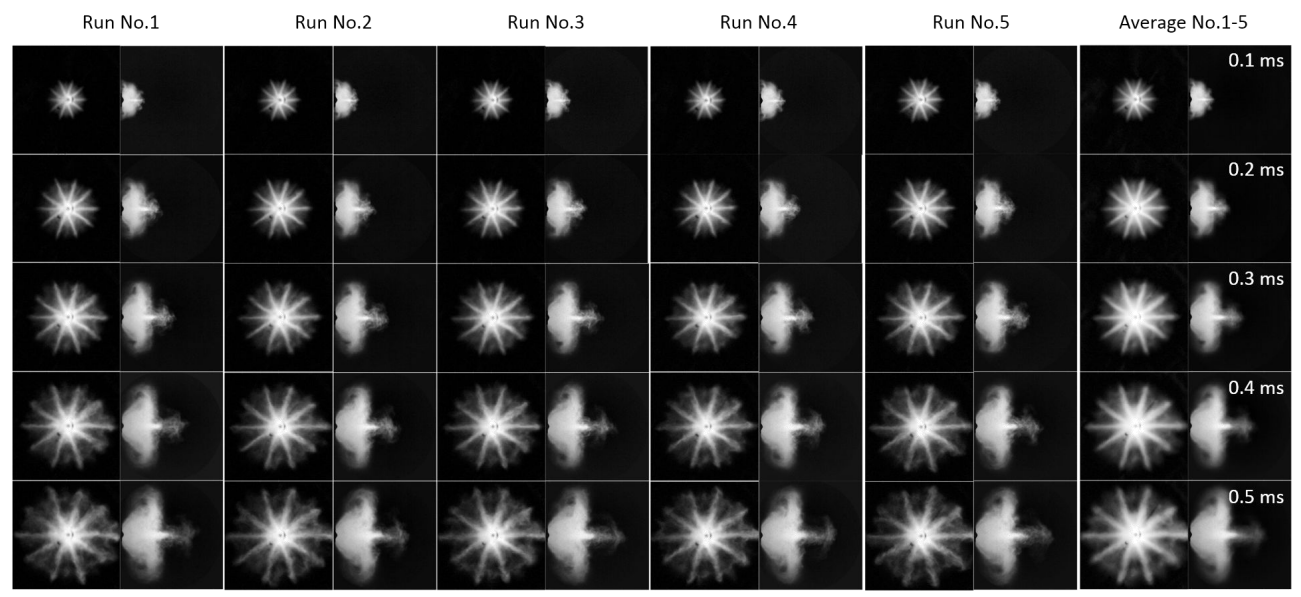

Figure 3: Comparison of individual sprays and averaged spray, $T_{\text {fuel }}=120^{\circ} \mathrm{C}, R_{p}=0.05$ 


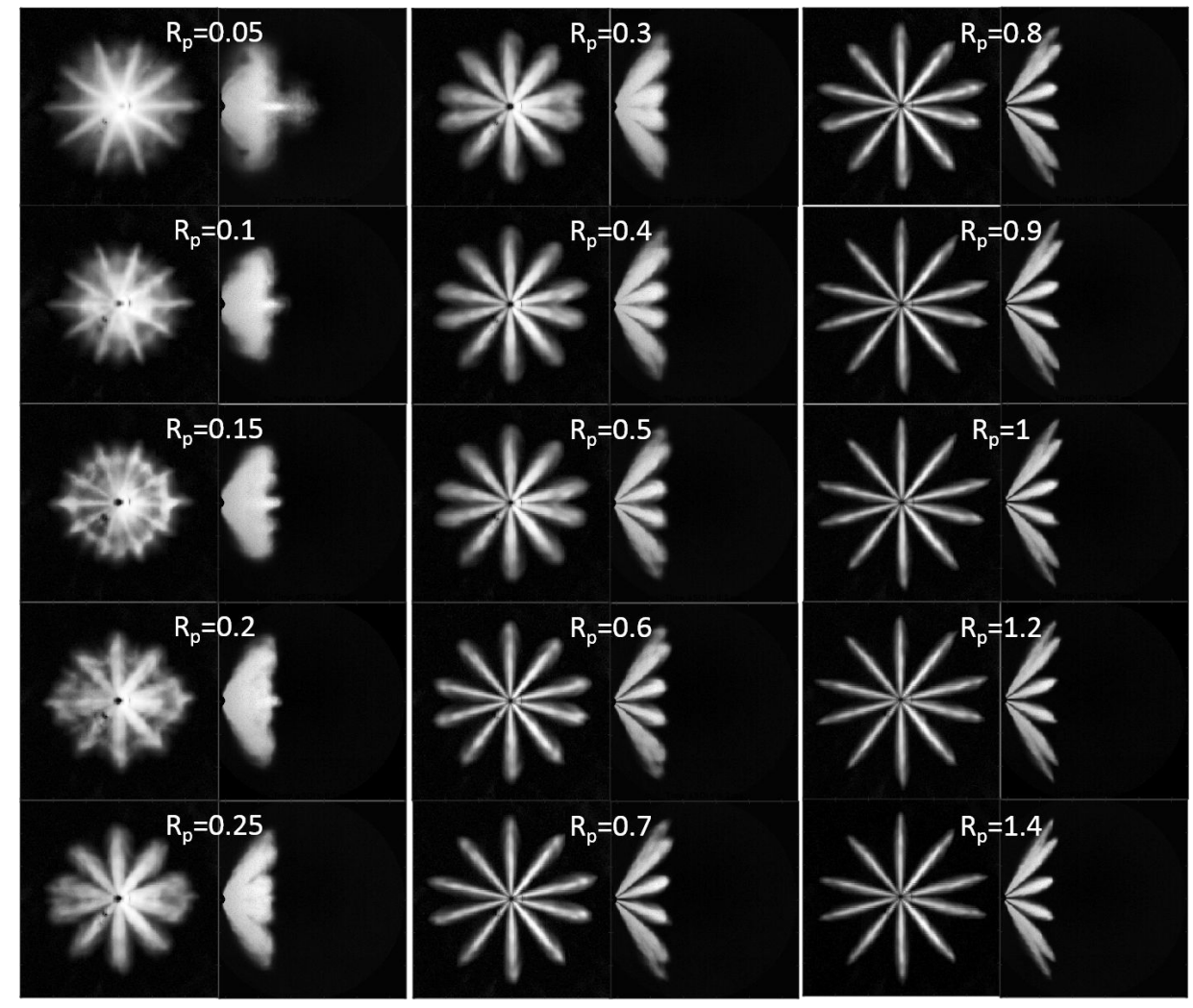

Figure 4: Change of spray morphology with $R_{p}, T_{\text {fuel }}=120^{\circ} \mathrm{C}$, Time aSOI $=0.3 \mathrm{~ms}$ 


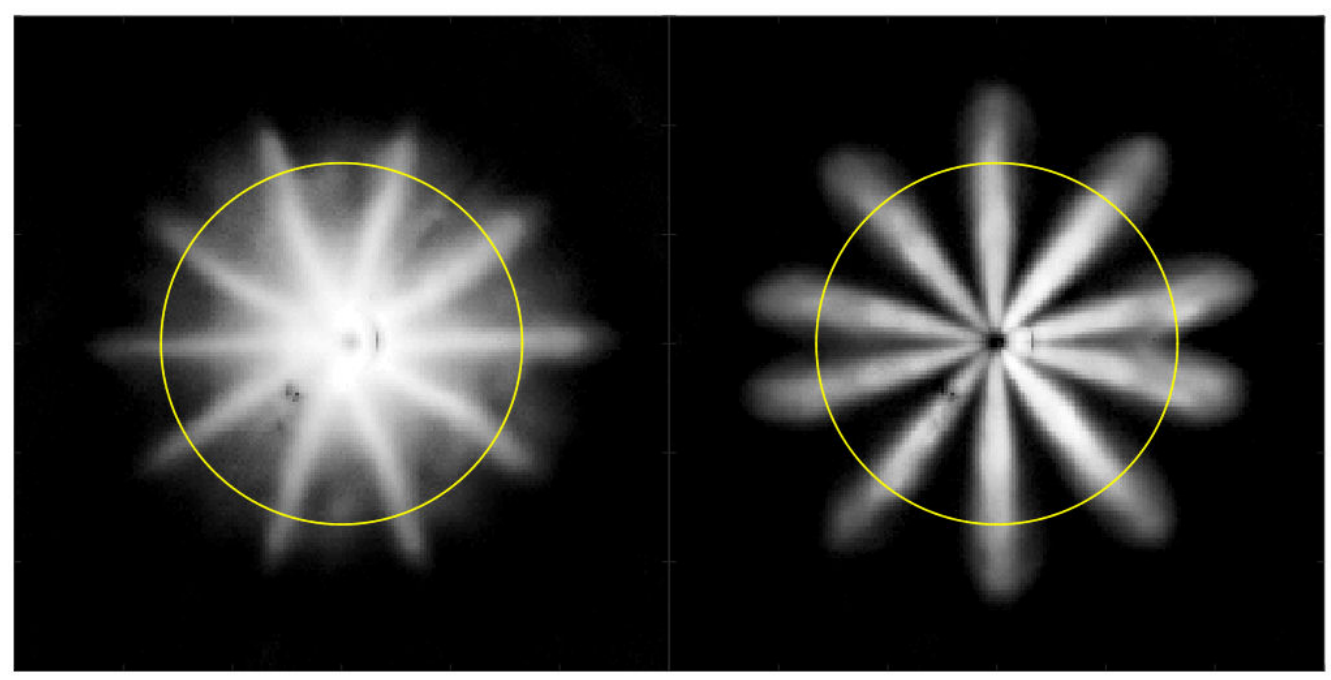

(a)

(b)

Figure 5: Shift of plume position $T_{\text {fuel }}=120^{\circ} \mathrm{C}$, Time $a S O I=0.3 \mathrm{~ms}$ (a) $R_{p}=0.05$; (b) $R_{p}=0.4$ 


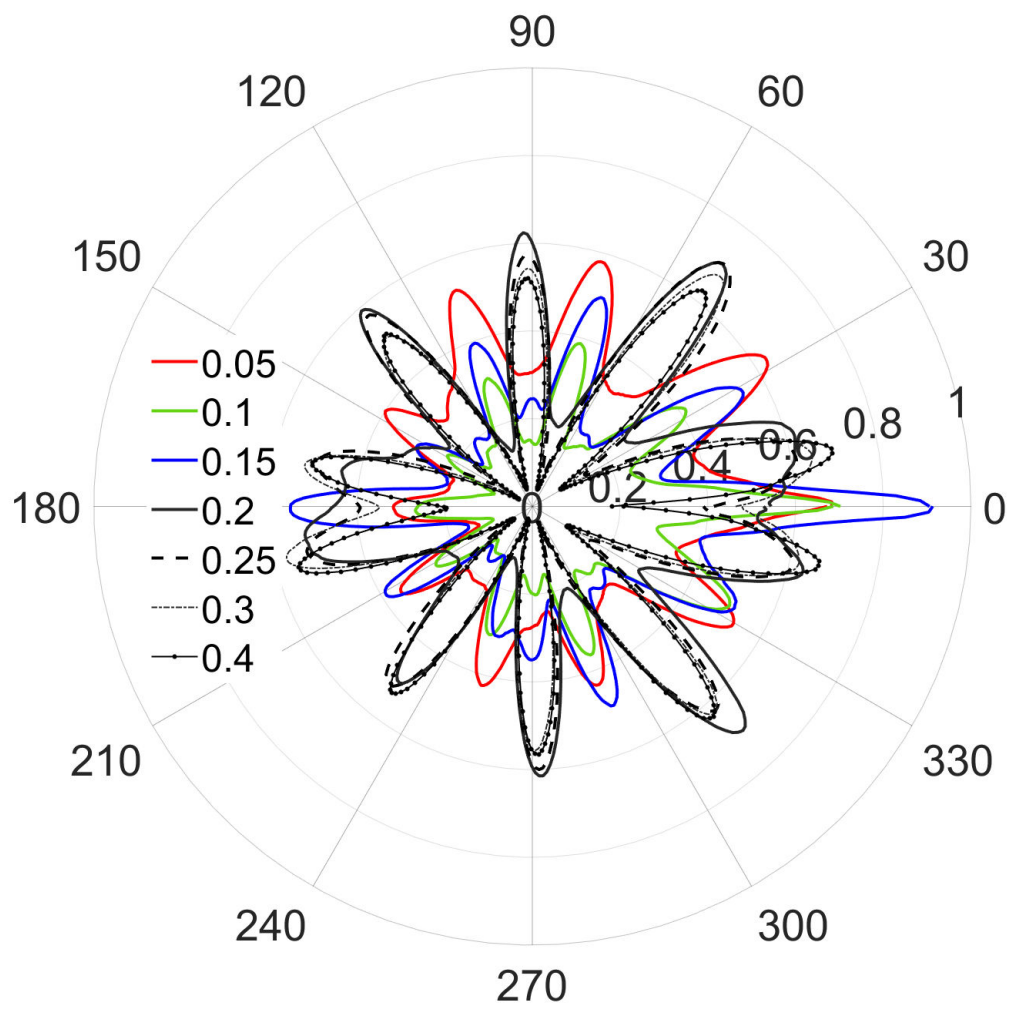

Figure 6: Shift of plume position $T_{\text {fuel }}=120^{\circ} \mathrm{C}$, Time $a S O I=0.3 m s$ : Intensity along marked circle in Figure $5, R_{p}$ from 0.05 to 0.4 . 


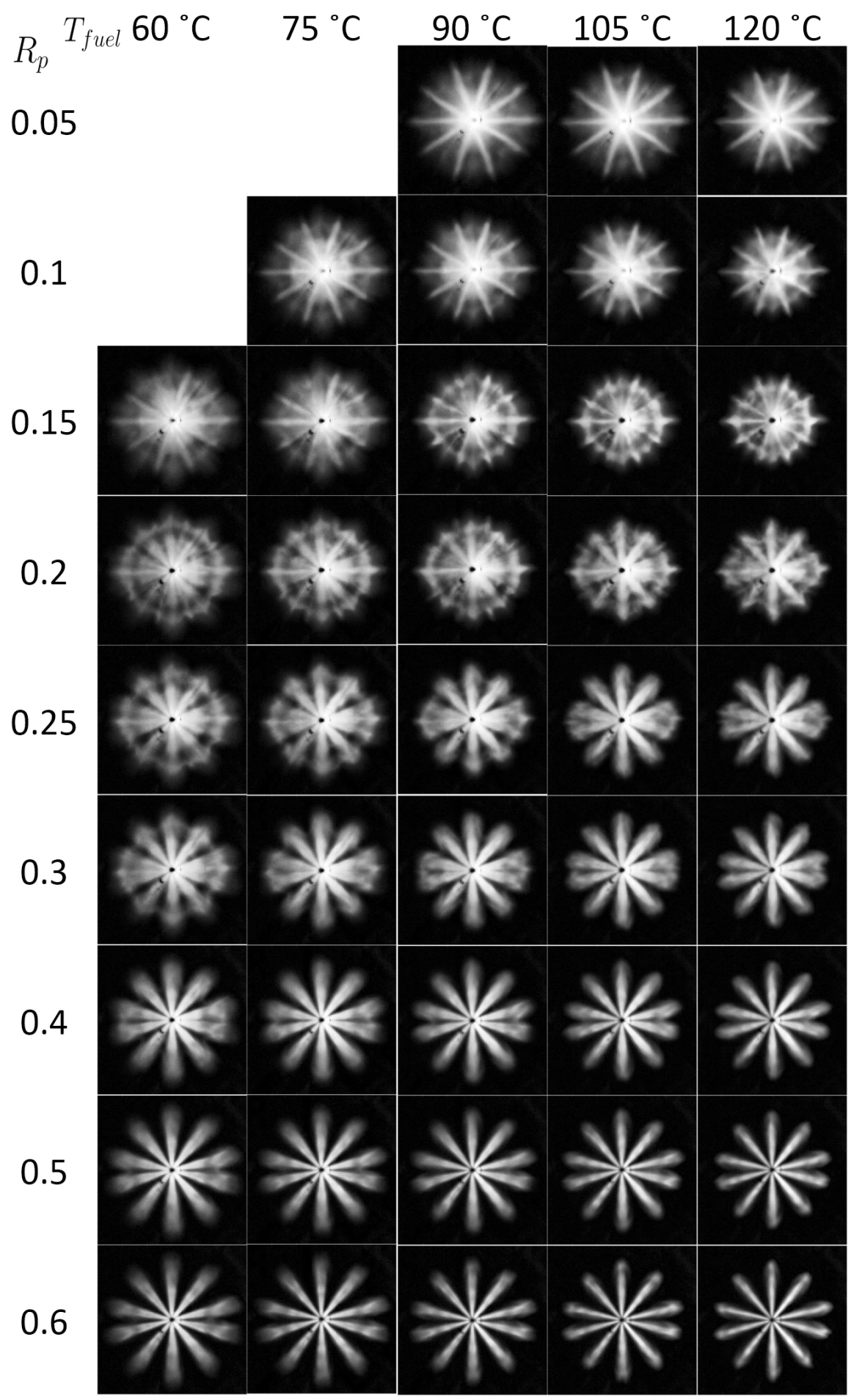

33

Figure 7: Effect of fuel temperature on spray morphology using front view Mie-scattering technique, Time aSOI $=0.3 \mathrm{~ms}$ 


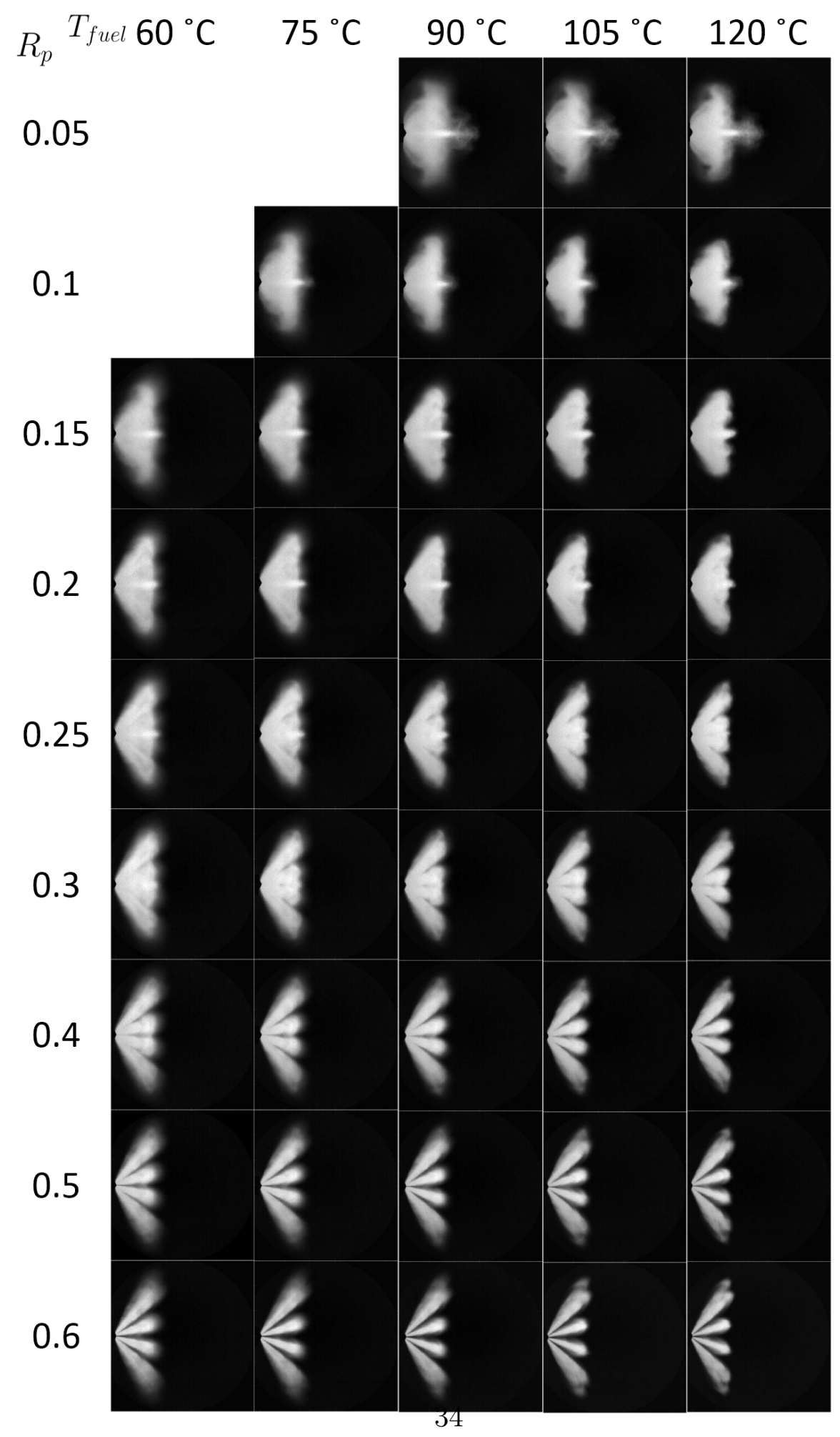

Figure 8: Effect of fuel temperature on spray morphology using side view DBI technique, Time $a S O I=0.3 \mathrm{~ms}$ 


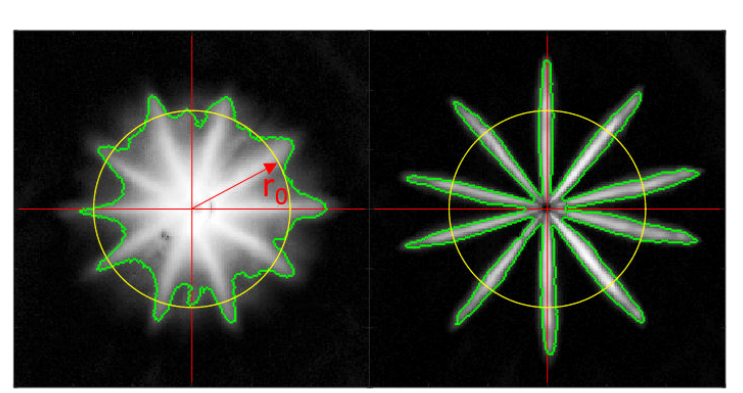

(a)

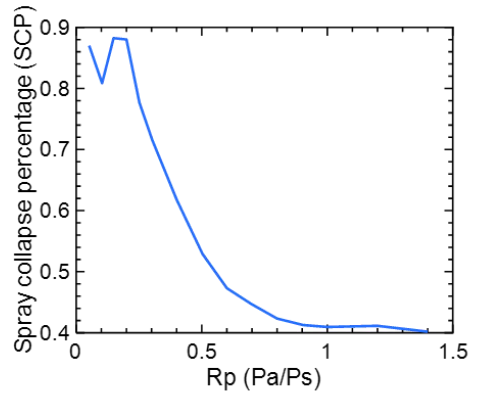

(c)

Figure 9: SCP based criterion (Time aSOI $=0.3 m s$, global thresh based on Otsu's method[33], $r_{0}$ is equivalent radius defined at the most super-heated case at this fuel temperature.(a) $R_{p}=0.05 ;(\mathrm{b}) R_{p}=1.4 ;(\mathrm{c}) \mathrm{SCP}$ with regard to $R_{p}$
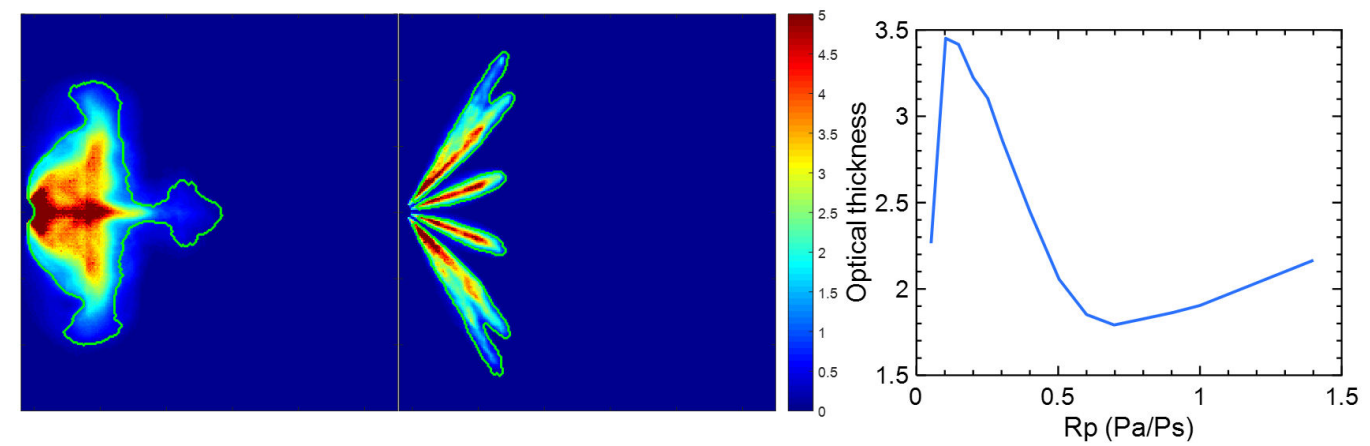

Figure 10: Optical thickness based criterion(Time aSOI $=0.3 \mathrm{~ms}$, global thresh based on Otsu's method. (a) $R_{p}=0.05$; (b) $R_{p}=1.4$; (c)Optical thickness with regard to $R_{p}$. 


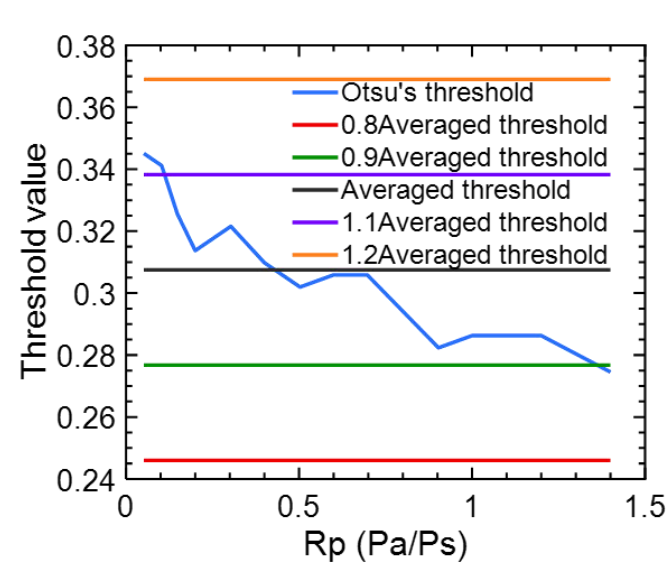

(a)

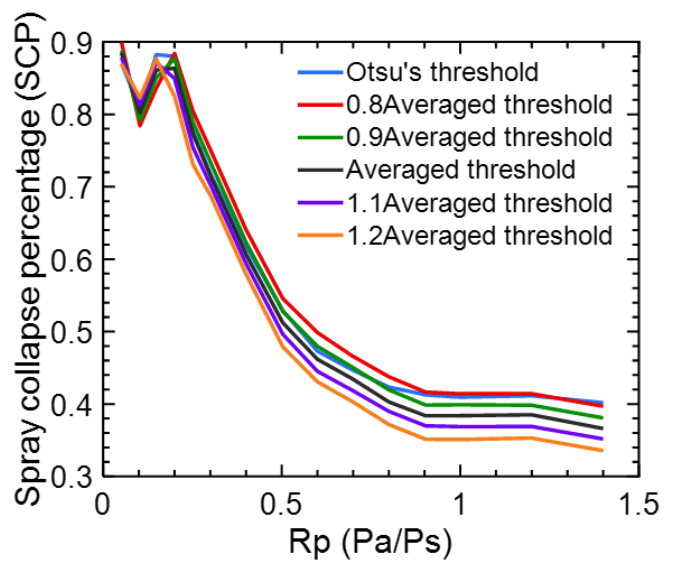

(b)

Figure 11: Sensitivity of SCP based criterion on threshold value

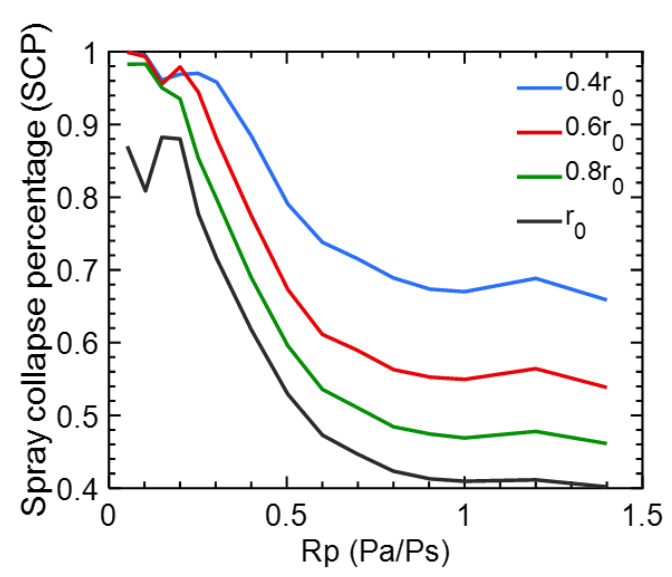

(a)

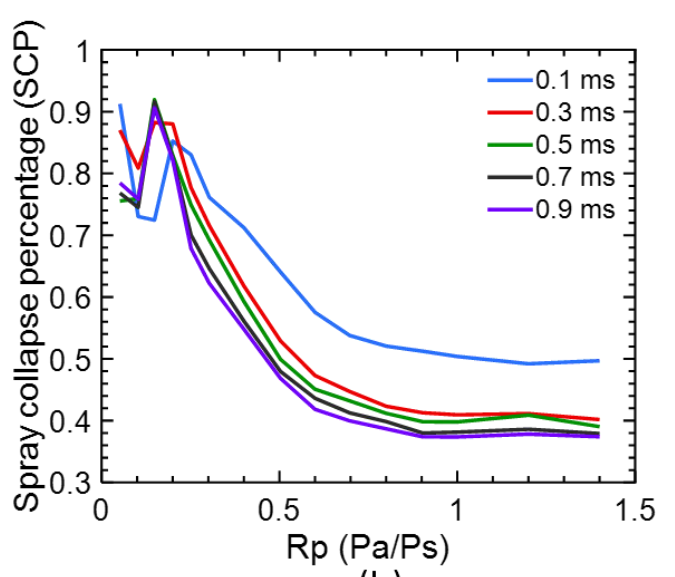

(b)

Figure 12: Sensitivity of SCP based criterion on: (a) pre-defined circle size; (b) instant time 


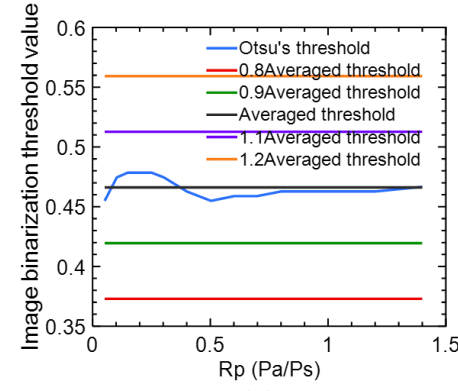

(a)

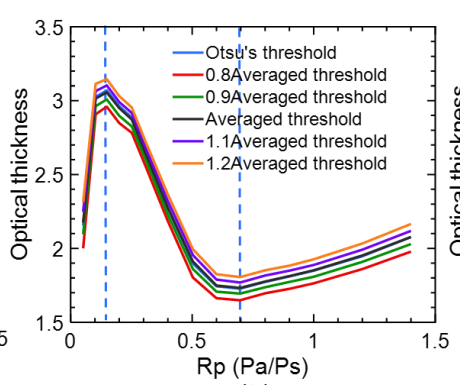

(b)

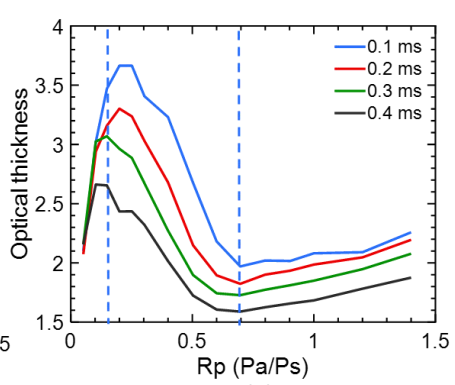

(c)

Figure 13: Sensitivity of averaged optical thickness $(\tau)$ based criterion to threshold value in image post processing and instant timing $T_{\text {fuel }}=120^{\circ} \mathrm{C}$ : (a) Time aSOI $=0.3 \mathrm{~ms}$, different threshold values; (b) Sensitivity to threshold value, Time aSOI $=0.3 \mathrm{~ms}$; (c) Sensitivity to instant timing, Otsu's threshold
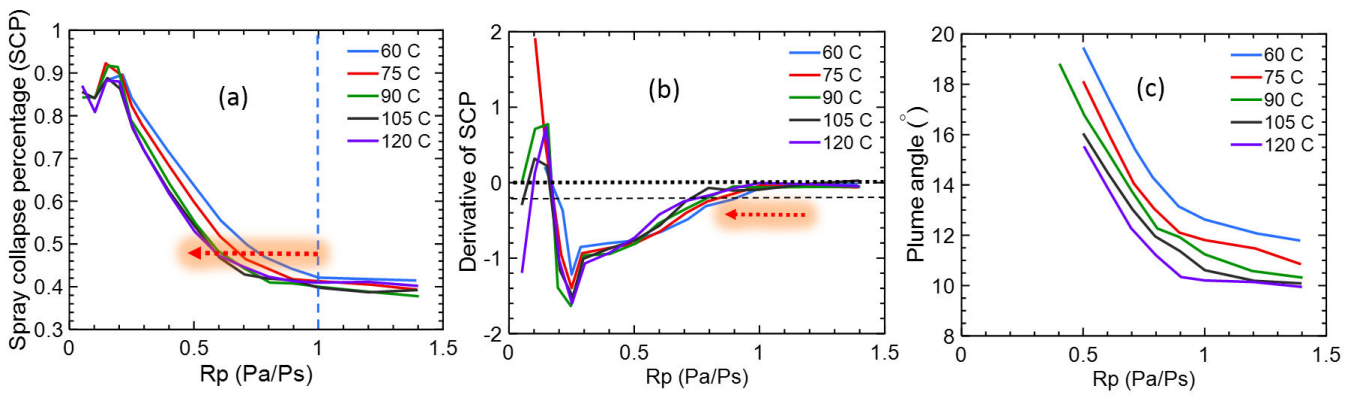

Figure 14: Criteria based on indicators from Mie-scattering image (Time aSOI $=0.3 \mathrm{~ms}$ ):

(a) SCP based; (b) Derivative of SCP; (c) Plume angle based 

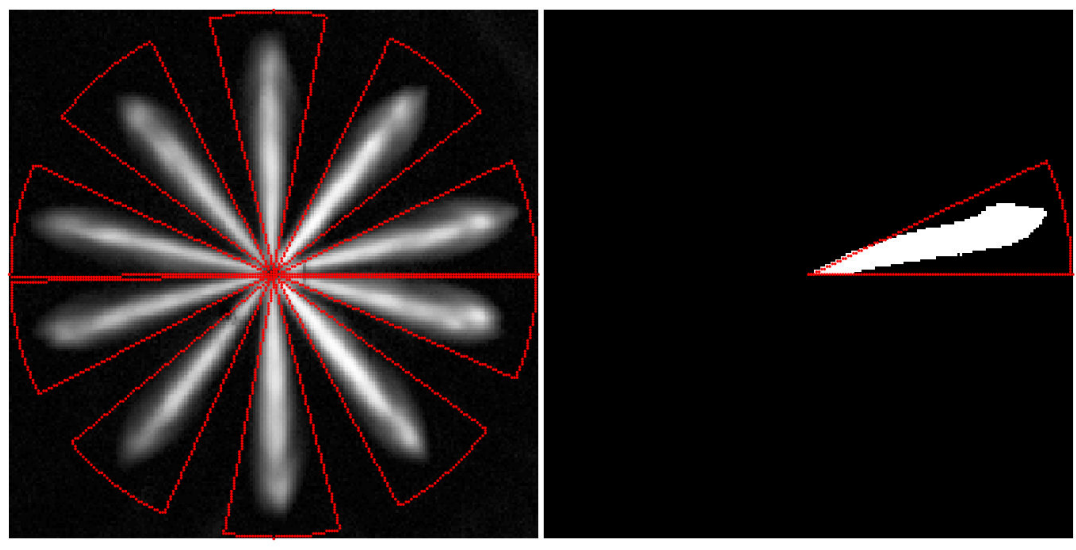

Figure 15: Plume segmentation and plume angle determination at Time aSOI $=0.3 \mathrm{~ms}$

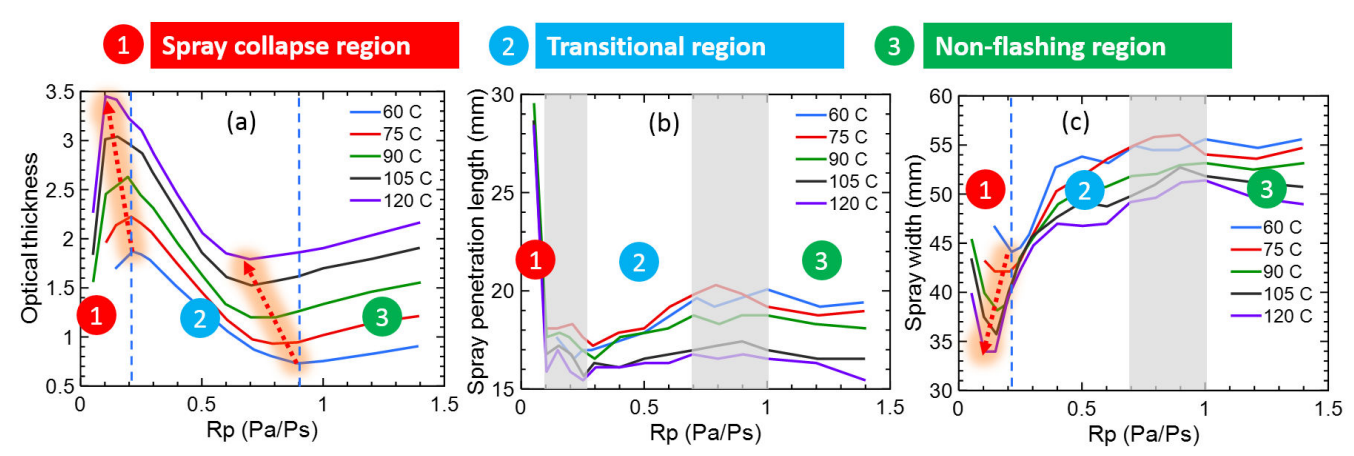

Figure 16: Criteria based on indicators from DBI image (Time aSOI $=0.3 \mathrm{~ms}$ ): (a) Optical thickness; (b) Spray penetration length; (c) Spray width 


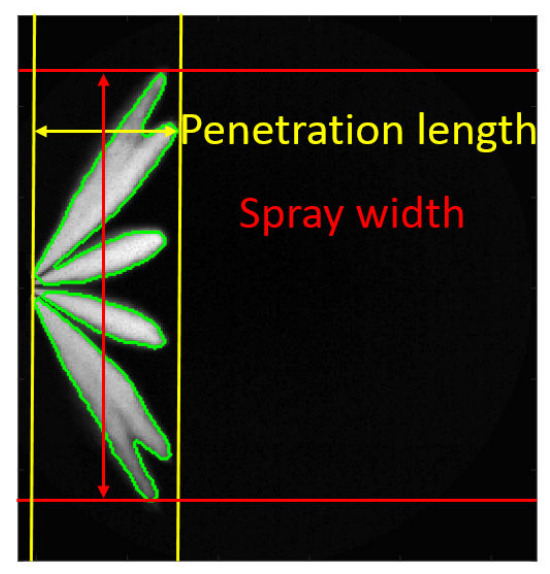

Figure 17: Definition of spray penetration length and spray width 